\title{
THE RUSSIAN ECONOMY IN EXPECTATION OF GROWTH ${ }^{1}$
}

\section{S.Tsukhlo}

Generalizing assessment of the existing economic situation (Adaptability index) has demonstrated in Q2 2016 the fact that the Russian economy persisted in high level of adaptability to the 2014-2016 crisis. By the end of two months of the quarter, the indicator hit the all-time maximum of $72 \%$. Estimates of demand and employments are the principal positive drivers of the Index.

The share of demand potential as "normal" in Q2 2016 hit 54\% following 45\% in Q1. At the same time, $42 \%$ of enterprises consider current demand volumes for their products as insufficient, which a maximum for the recent seven quarters.

The share of "normal" responses regarding the headcount went up from 76 to $80 \%$. The remaining $20 \%$ were distributed as follows: $12 \%$ as excessive employment and $8 \%$ as insufficient employment. The customary balance remains positive

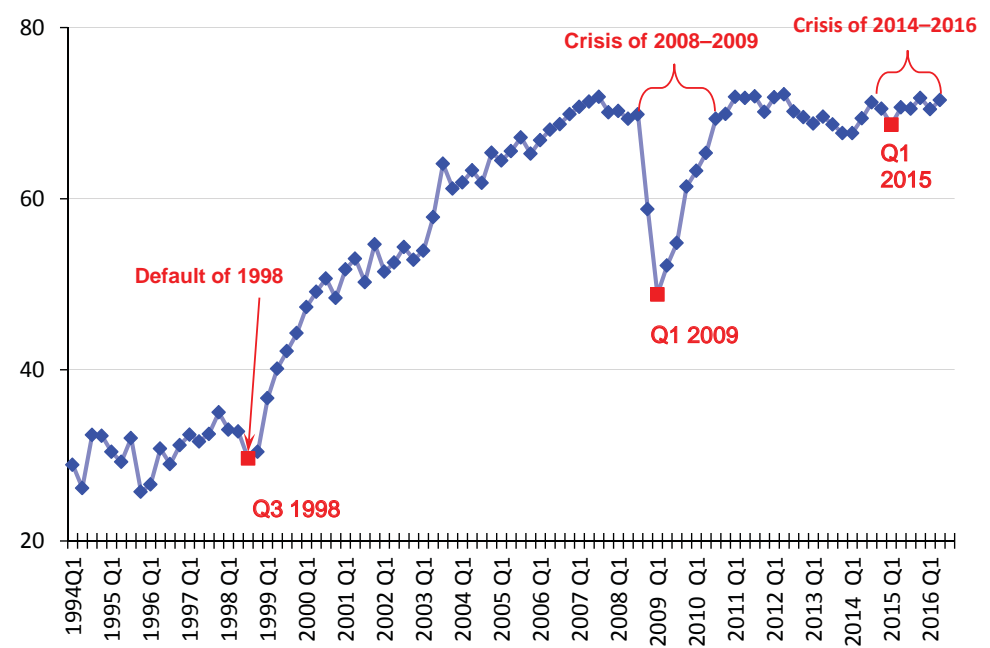

Fig. 1. Adaptability Index (normal) of industry, 1994-2016, \% (share of enterprises estimating their indicators as "normal") (+4 p.p.) and happened to me maximum since Q1 2010. In the turn of 2010 to date 25 quarters, Russian industry oftener operated in the wake of a significant shortage of personnel than a meager surplus. The maximum surplus was registered in Q2 2016.

Stocks of finished products, according to the businesses, remain in mainly normal volumes. The share of responses "normal" since the outset of the 2014-2016 crisis does not fall below 70\% on average for a quarter (in Q2 2016, it constituted $72 \%$ ) and the remaining $27-30 \%$ register moderate and far from crisis predominance of responses "above normal." Relying on the official statistics related to stocks, which releases data on the reduction of their physical volumes, and then Russian industry is conducting a highly rational policy of managing stocks by purposefully and orderly cutting their volumes in the context of extremely unlikely hike for their products.

The same situation is developing in industry regarding stocks of industrial inputs. The 2014-2016 crisis has not resulted in any crisis changes of enterprises' responses regarding their volumes. The share of responses "normal"

1 This paper was originally published in Online Monitoring of Russia's Economic Outlook No.11(29). 
in late 2014-turn of 2015 demonstrated a far from crisis stability. During last four quarters, the indicator remains in the range of $77-80 \%$, which were hard for businesses to ensure during previous non-crisis years. The balance of remaining responses ("above normal" - "below normal") in 2014-2016 stays in the range of 13- -7 points, which also does not look like the crisis values of 2009 indicator (when balance fell to -26 points or its prior to default values $-70--60$ points).

Thus, industry has never experienced shortages with supply of industrial inputs in the context of the current crisis. This conclusion is supported by another indicator - downward pressure on output by a shortage of raw and other materials. According to businesses, this factor during recent crisis years stayed at all-time minimum of its negative impact on industrial growth for the entire monitoring period (1995-2016). Merely 8-9\% of enterprises indicate in 2012-2016 the shortage of industrial inputs as an obstruction to their output growth.

Estimates of existing industrial capacities have positively contributed to the Adaptability Index. It is true that the share of enterprises with sufficient capacities went up barely by 1 p.p., however $28 \%$ of enterprises report excess of capacities. Business surveys have not registered such a significant share of domestic producers with excess capacities during recent 13 quarters. In other words, we have received the maximum value for the indicator in the wake of the current crisis. Thus, industry is much better secured with capacities for potential growth than with personnel.

Estimates of enterprises to a certain degree depend on the production. Although such dependence is not observed everywhere. Although, traditionally the largest Russian producers face fewer problems with recruitment but the lag of enterprises of other sizes constitutes as a rule not more than 10 p.p. In 2016, it fell to 5 p.p.

Sufficiency of industrial capacities to a lesser degree depend on the size of an enterprise. Recently this indicator does not fall below $90 \%$ for enterprises of all sizes and along first two quarters of 2016, it stays in the range of 92-94\%.

However, on the whole, adaptability of producers to the economic realities still depends on the size of an enterprise (Fig. 2). The Adaptability Index demonstrates higher values in the group of the largest (over 1,000 workers) enterprises. In Q2 2016, it hit an all-time maximum of $75 \%$ in this group. Small and medium enterprises retain inferior potential for adaptability to crisis. Since Q2 2010, the Adaptability Index in the latter group stays in the range of $57-62 \%$.

Estimates of demand secure major gap of the Index in the group of largest enterprises. In 2016, this group boasts of sales satisfaction to the tune of $54 \%$,

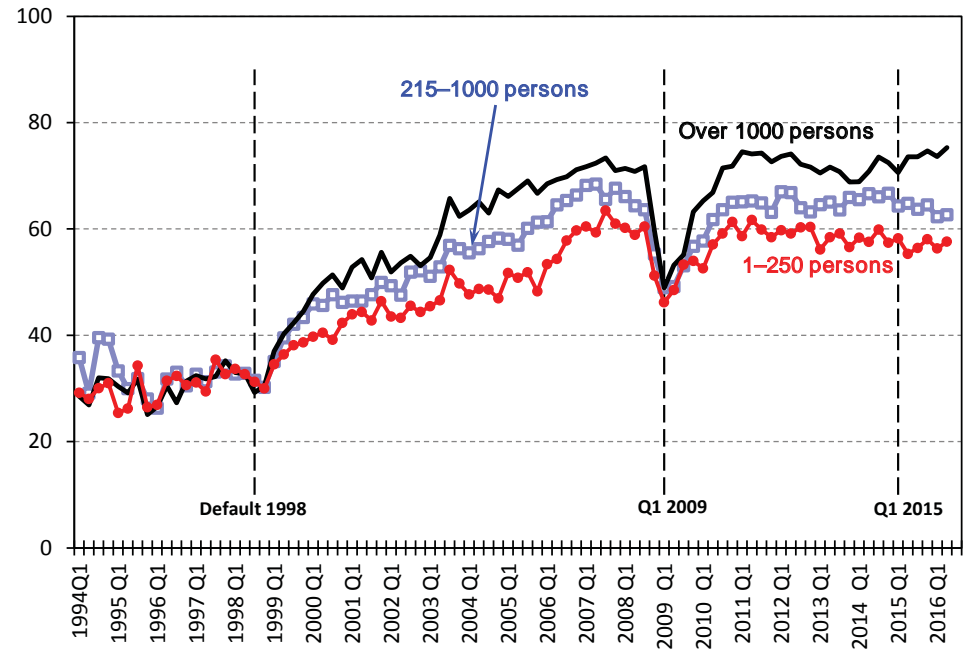

Fig.2. Adaptability indices along enterprises' sizes, 1994-2016, $\%$ (share of enterprises, estimating their indicators as "normal") 
meanwhile small and medium enterprises - merely $24 \%$. Gap of 30 p.p. was also registered in 2015.

The next factor, which determines leadership of the largest enterprises, is sufficiency of industrial inputs. Along the level of their normal sufficiency, the gap constitutes 25 p.p. Advantage of responses "normal" regarding estimates of stocks of finished products and financial and economic state of enterprises comes in each case to 18 p.p. 